\title{
Ultrasound Diagnosis of Hepatic Steatosis as a Surrogate for Atherosclerosis
}

Authors

Affiliations

\section{S. Guth ${ }^{1}$, E. Windler ${ }^{2}$, U. Leise ${ }^{1}$, C. M. Bamberger}

${ }^{1}$ Medical Prevention Center Hamburg, University Hospital Hamburg-Eppendorf, Hamburg, Germany

${ }_{2}^{2}$ Präventive Medizin, University Hospital Hamburg-Eppendorf, Universitäres Herzzentrum Hamburg, Hamburg, Germany
Keywords

- ultrasound 2D

- arteriosclerosis

- health policy and practice

received $\quad 10.08 .2015$

accepted $\quad 13.12 .2015$

Bibliography

DOI http://dx.doi.org/

10.1055/s-0035-1569419

Published online:

March 1, 2016

Ultrasound International Open

2016; 2: E27-E31

(c) Georg Thieme Verlag KG

Stuttgart · New York

ISSN 2199-7152

\section{Correspondence}

\section{Dr. Sabine Guth}

Medical Prevention Center

Hamburg

University Hospital Hamburg-

Eppendorf

Falkenried 88

20251 Hamburg

Germany

Tel.: +49/40/468636113

Fax: +49/40/468636122

guth@mpch.de

\begin{abstract}
$\nabla$

Introduction: Ultrasonography has become available to most physicians in primary care. Increasingly hepatic steatosis becomes a chance finding, which has been shown to be associated with cardiovascular risk factors, surrogates of vascular disease, and vascular events. This study tries to answer the question whether it is justified to recommend a cardiovascular workup in response to the incidental finding of hepatic steatosis in asymptomatic healthy individuals.

Methods: The data of 259 healthy women and 561 men aged 19-93 years, who consecutively underwent a primary preventive check-up, were retrospectively analyzed. Ultrasonography for diagnosis of hepatic steatosis, determination of the maximal intima media thickness (IMT) and plaques of the carotid arteries was performed by a single certified physician according to conventional criteria.
\end{abstract}

\section{Introduction \\ $\nabla$}

Ultrasonography has become a widespread diagnostic tool available to most general practitioners and internists. Whether used for a specific diagnostic or a preventive workup, it may yield information that goes beyond the specific question asked. One example of great impact is the chance finding of atherosclerosis which may be a sign of developing cardiovascular disease. In recent years an increasing prevalence of hepatic steatosis has been noticed. It is well established that hepatic steatosis is associated with risk factors for atherosclerosis, particularly type 2 diabetes and the components of the metabolic syndrome $[1,2]$. In several studies and various populations an association between non-alcoholic fatty liver disease (NAFLD) and surrogates of cardiovascular disease has been observed [3].
Results: Hepatic steatosis was found in $28.3 \%$ men and $7.7 \%$ women. In $88 \%$ the steatosis was judged to be mild. These individuals differed from those without hepatic steatosis in body mass index, ALAT, GGT, HbA1c, fasting glucose, triglycerides, HDL and lipoprotein(a). The IMT was higher and plaques were more prevalent. In logistic regression analysis hepatic steatosis was a highly significant predictor of the presence of an IMT $>0.8 \mathrm{~mm}$ or carotid plaques besides age and sex. This was also the case in analyses including BMI, or multiple risk factors, which added only lipoprotein(a) as a predictor.

Conclusion: The incidental diagnosis of hepatic steatosis is a strong indicator for the presence of cardiovascular risk factors and even signs of developing atherosclerosis. Thus, the recommendation of further cardiovascular workups seems appropriate.
In this context a strong correlation between hepatic steatosis diagnosed by ultrasonography or liver histology and intima media thickness has been documented $[4,5]$. Targher et al. found a significantly increased intima media thickness in patients with type 2 diabetes with a sonographically diagnosed non-alcoholic fatty liver as compared to diabetic patients with a normal liver [6]. Also, Ramilli et al. [4] demonstrated a correlation between hepatic steatosis detected by ultrasound with increased body mass index, arterial hypertension, and elevated intima media thickness and the presence of carotid plaques in Italian outpatients referred for an abdominal ultrasound for any reason. In Korea Choi et al. [7] found a strong association of hepatic steatosis with carotid plaques by ultrasound in randomly consecutive patients, even after adjustment for age, sex, BMI, and the individual factors of a 
metabolic syndrome. Targher et al. went even one step further and showed an increased risk for future cardiovascular events in patients with hepatic steatosis $[5,8]$.

This study intends to investigate into the potential of abdominal ultrasound to predict the prevalence of atherosclerosis in primarily healthy subjects. This may add to the question of whether it is justified and advisable to recommend a cardiovascular workup to patients with hepatic steatosis, despite no cardiovascular problems. For this purpose, the data of 820 primarily healthy individuals presenting with no acute symptoms in a preventive medical check-up setting were retrospectively analysed, and the association of hepatic steatosis diagnosed by ultrasonography with risk factors for atherosclerosis and increased carotid intima media thickness or plaques was evaluated.

\section{Materials and Methods}

$\nabla$

The Center for Preventive Medicine Hamburg at the University Hospital Hamburg-Eppendorf offers medical check-ups for preventive medical advice, but no workups of acute diseases. Thus, primarily individuals in a healthy state are seen who may have long-standing medication for stable chronic diseases, though. Between March 2006 and July 2007 consecutively 259 women and 561 men aged 19-93 years free of acute symptoms or diseases were included in this retrospective explorative analysis.

The check-up included a physical examination, measurements of blood pressure and body mass index (BMI), and routine laboratory values determined by standard procedures including total cholesterol, HDL cholesterol, LDL cholesterol, triglycerides and lipoprotein(a), fasting glucose, HbA1c, and liver enzymes (aspartate aminotransferase (ASAT), alanine aminotransferase (ALAT), and gammaglutamyl transferase (GGT)). Hypertension was defined by a systolic blood pressure $\geq 140 \mathrm{mmHg}$ or diastolic of $\geq 90 \mathrm{mmHg}$ or being on antihypertensive therapy.

Ultrasonographic investigations were performed by a single experienced and certified internist certified by the German association of ultrasound in medicine (DEGUM) level III using a high end device (Siemens Acuson Antares premium edition, Siemens, Erlangen, Germany) with a curved 2-6 MHz array for the abdominal organs and a linear 5-9 $\mathrm{MHz}$ array for the examination of the extracranial vessels and taking the maximum intima media thickness of the distal wall of one of the common carotid arteries.

The diagnosis of hepatic steatosis by ultrasound was graded according to the criteria established by Joseph et al. 1991 [9]: "mild steatosis": slightly hyperechoic, but homogenous echo structure; "moderate steatosis": hyperechoic structure, dorsal diminishing of echo signal and beginning rarefication of hepatic vessels; "severe steatosis": hyperechoic and irregular parenchym structure, suspected fibrocirrhotic change, irregular margin and reduced elasticity.

An abnormal intima media thickening refers to a maximal intima media thickness of $>0.8 \mathrm{~mm}$ of the far wall of the common carotid artery [10-12]. Plaques were defined as atheromatous, calcificated or mixed circumscribed wall thickenings, and stenoses were defined as wall irregularities taking more than $60 \%$ of the vessel lumen graded according to Hennerici et al. [13] and Touboul et al. 2012 [14].

Statistical analyses were performed using the XLSTAT software 2012 (Addinsoft Germany). For comparing the prevalence of characteristics of individuals with (cases) or without (controls) a fatty liver, the Mann-Whitney test was applied for continuous parameters and the Chi-square test for discontinuous data. Multivariate analyses were performed by logistic regression. P-values of $<0.05$ were regarded significant.

\section{Results}

$\nabla$

Data of 820 patients were analysed. The basic characteristics of 561 men and 259 women with (cases) or without (controls) hepatic steatosis as diagnosed by abdominal ultrasound are given in Table 1. In 154 men (28.3\%) and 20 women (7.7\%) hepatic steatosis was diagnosed by abdominal ultrasound. $88 \%$ of these patients had mild steatosis [9]. Only 2 women and 18 men were judged to have moderate steatosis, and 1 man with severe hepatic steatosis was suspected to have fibrocirrhosis.

Cases and controls were of comparable age ( $\bullet$ Table 1 ). In line with the higher ultrasonographic classification of hepatic steatosis in cases, ALAT and GGT were also on average higher in both male and female cases than in controls ( $\bullet$ Table 1 ). Correspondingly, the percentage of those with ALAT or GGT above the upper limit of normal was higher in cases of both genders.

Male and female cases also differed significantly from controls in their BMI, fasting blood sugar, HbA1c, triglycerides and HDL cholesterol, while LDL cholesterol was not significantly different in both sexes ( $\bullet$ Table 1 ). The mean BMI was 2.5 and $5.9 \mathrm{~kg} / \mathrm{m}^{2}$ higher in male and female cases, respectively, compared to that of controls. $55.8 \%$ of male cases were overweight (BMI $\geq 25 \mathrm{~kg} / \mathrm{m}^{2}$ ) and $26.0 \%$ obese (BMI $\geq 30 \mathrm{~kg} / \mathrm{m}^{2}$ ) in contrast to $42.2 \%$ and $12.6 \%$ of controls, respectively. Of female cases $52.6 \%$ were overweight and $36.8 \%$ obese, compared to $22.1 \%$ and $4.4 \%$ controls, respectively. The 2 women with moderately fatty liver were obese, as were 13 of the 20 men with moderately to severe fatty liver. Only 2 men with moderately fatty liver were of normal weight according to the conventional BMI classification.

In line with differences in weight, cases were characterized more often by components of the metabolic syndrome as defined by the International Diabetes Federation [15], i.e., elevated triglycerides $>150 \mathrm{mg} / \mathrm{dl}$, and HDL cholesterol $<50$ or 40 $\mathrm{mg} / \mathrm{dl}$ for women and men, respectively ( $\bullet$ Table 2 ). Fasting glucose $\geq 100 \mathrm{mg} / \mathrm{dl}$ and hypertension were more prevalent in cases, though only in women the differences reached significance.

An IMT of $>0.8 \mathrm{~mm}$ or plaques in the common carotid arteries were more prevalent in male cases $(36.4 \%)$ than in controls (29.0\%) ( $p=0.092)$, yet the difference between cases $(40.0 \%)$ and controls $(16.7 \%)$ reached only significance in women $(\mathrm{p}=0.001)$. Also, plaques in the common carotid arteries or bulbi were numerically more frequent in male cases $(31.2 \%)$ than in controls $(24.1 \%)(p=0.088)$, and in female cases $(40.0 \%)$ and controls $(16.7 \%) \quad(p=0.438)$, which, however, did not reach significance in both genders. Even though elevated IMT has often been associated with fatty liver especially in men, it frequently occurred also in individuals without a fatty liver as well. Still, the logistic regression analysis revealed male sex and hepatic steatosis besides age as highly significant predictors of an IMT $>0.8 \mathrm{~mm}$ or the manifestation of carotid plaques detected by ultrasound. Excluding BMI from the analysis did not materially alter the results. In a multivariate analysis including major cardiovascular risk factors, besides age only hepatic steatosis and elevated lipoprotein(a) proved to be statistically significant predictors of the presence of elevated IMT or carotid plaques in both genders despite multiple adjustments ( $\odot$ Table 3 ). 
Table 1 Characteristics of individuals with and without hepatic steatosis diagnosed by ultrasonography and the significance of differences of the means.

\section{Men}

$n=561$

Age [years]

BMI $\left[\mathrm{kg} / \mathrm{m}^{2}\right]$

Fasting blood sugar [mg/dl]

Hemoglobin A1c [\%]

Total cholesterol [mg/dl]

LDL-cholesterol [mg/dl]

HDL-cholesterol [mg/dl]

Triglycerides [mg/dl]

ASAT (GOT) [IU/I]

ALAT (GPT) [IU/I]

GGT [IU/I]

Women

$n=259$

Age [years]

BMI $\left[\mathrm{kg} / \mathrm{m}^{2}\right]$

Fasting glucose $[\mathrm{mg} / \mathrm{dl}]$

Hemoglobin A1c [\%]

Total cholesterol [mg/dl]

LDL-cholesterol [mg/dl]

HDL-cholesterol [mg/dl]

Triglycerides [mg/dl]

ASAT (GOT) [IU/I]

ALAT (GPT) [IU/I]

GGT [IU/I]

\begin{tabular}{|c|c|c|}
\hline \multicolumn{3}{|c|}{ Controls } \\
\hline \multicolumn{3}{|c|}{$n=407$} \\
\hline Mean & Median & $1 \mathrm{SD}$ \\
\hline 56.6 & 57.0 & 12.0 \\
\hline 25.5 & 25.2 & 2.8 \\
\hline 89.1 & 87.0 & 15.2 \\
\hline 5.5 & 5.5 & 0.5 \\
\hline 206.3 & 203.0 & 37.6 \\
\hline 122.2 & 118.5 & 34.1 \\
\hline 63.4 & 61.0 & 16.3 \\
\hline 104.1 & 86.0 & 63.1 \\
\hline 27.9 & 27.0 & 7.0 \\
\hline 27.8 & 25.0 & 11.3 \\
\hline 33.4 & 25.0 & 28.2 \\
\hline \multicolumn{3}{|c|}{ Controls } \\
\hline \multicolumn{3}{|c|}{$n=239$} \\
\hline Mean & Median & $1 \mathrm{SD}$ \\
\hline 57.0 & 57.0 & 12.3 \\
\hline 23.2 & 23.0 & 3.5 \\
\hline 84.6 & 84.0 & 11.5 \\
\hline 5.5 & 5.5 & 0.4 \\
\hline 217.5 & 216.0 & 36.3 \\
\hline 115.5 & 112.0 & 34.6 \\
\hline 84.5 & 83.0 & 20.9 \\
\hline 84.4 & 76.0 & 36.3 \\
\hline 25.5 & 24.0 & 8.2 \\
\hline 21.2 & 19.0 & 9.3 \\
\hline 24.8 & 18.0 & 23.5 \\
\hline
\end{tabular}

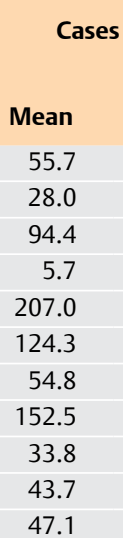

Cases with hepatic steatosis

$n=154$

Median

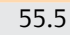

27.3

91.5

5.6

208.0

124.0

53.0

129.0

30.0

37.0

37.5

\section{Cases with hepatic steatosis}

$\mathbf{n}=\mathbf{2 0}$

Mean Median 1 SD

$\begin{array}{lll}61.0 & 60.0 & 5.1\end{array}$

29.2

100.1

29.5

97.0

5.7

233.0

137.0

61.0

143.0

24.0

28.0

31.0

$\begin{array}{r}1 \text { SD } \\ 10.1 \\ 3.6 \\ 19.5 \\ 0.6 \\ 37.7 \\ \hline 35.4 \\ 14.1 \\ 77.0 \\ 13.3 \\ \hline 26.5 \\ \hline 34.8\end{array}$

1 SD

3.6

19.5

0.6
37.7

35.4

4.1

77.0

13.3

34.8

sis

SD
5.1

3.1

15.2

0.4

35.4

43.2

25.9

83.0

7.6

16.9

39.7
Significance

p-value

n.s.

$<0.0001$

0.0004

0.004

n.s.

n.s.

$<0.0001$

$<0.0001$

$<0.0001$

$<0.0001$

$<0.0001$

Significance

p-value

n.s.

$<0.0001$

$<0.0001$

0.005

n.s.

n.s.

$<0.0001$

$<0.0001$

n.s.

$<0.0001$

0.018

\begin{tabular}{|c|c|c|c|}
\hline Men & $\begin{array}{c}\text { Controls } \\
\text { [\%] }\end{array}$ & $\begin{array}{l}\text { Cases with hepatic steatosis } \\
\text { [\%] }\end{array}$ & $\begin{array}{l}\text { Significance } \\
\text { p-value }\end{array}$ \\
\hline $\mathrm{BMI} \geq 25\left[\mathrm{~kg} / \mathrm{m}^{2}\right]$ & 54.9 & 81.8 & $<0.0001$ \\
\hline Hypertension [\%] & 35.0 & 42.2 & 0.113 \\
\hline Fasting glucose $\geq 100 \mathrm{mg} / \mathrm{dl}]$ & 19.0 & 26.3 & 0.06 \\
\hline LDL-cholesterol $\geq 130 \mathrm{mg} / \mathrm{dl}$ & 39.1 & 41.1 & 0.673 \\
\hline HDL-cholesterol< $<0$ mg/dl & 20.8 & 36.8 & 0.0001 \\
\hline HDL-cholesterol $<40 \mathrm{mg} / \mathrm{dl}$ & 2.3 & 11.8 & $<0.0001$ \\
\hline Triglycerides $>150 \mathrm{mg} / \mathrm{dl}$ & 16.5 & 38.6 & $<0.0001$ \\
\hline ALAT (GPT) $>45 \mathrm{IU} / \mathrm{I}$ & 7.6 & 30.3 & $<0.0001$ \\
\hline GGT $>55 \mathrm{IU} / \mathrm{I}$ & 10.4 & 22.4 & 0.00025 \\
\hline $\mathrm{IMT}>0.8 \mathrm{~mm}$ & 29.0 & 36.4 & 0.092 \\
\hline Carotid plaque & 24.1 & 31.2 & 0.088 \\
\hline IMT >0.8 mm or carotid plaque & 33.7 & 41.6 & 0.082 \\
\hline Women & [\%] & [\%] & p-value \\
\hline $\mathrm{BMI} \geq 25\left[\mathrm{~kg} / \mathrm{m}^{2}\right]$ & 10.5 & 26.4 & $<0.0001$ \\
\hline Hypertension [\%] & 31.6 & 68.4 & 0.001 \\
\hline Fasting blood sugar $\geq 100 \mathrm{mg} / \mathrm{dll}]$ & 7.8 & 42.1 & $<0.0001$ \\
\hline LDL-cholesterol $\geq 130 \mathrm{mg} / \mathrm{dl}$ & 16.8 & 52.6 & 0.0002 \\
\hline HDL-cholesterol<50 mg/dl & 3.4 & 21.1 & 0.001 \\
\hline HDL-cholesterol $<40 \mathrm{mg} / \mathrm{dl}$ & 0.4 & 0.0 & 0.774 \\
\hline Triglycerides $>150 \mathrm{mg} / \mathrm{dl}$ & 6.5 & 47.4 & $<0.0001$ \\
\hline ALAT (GPT) $>34 I U / I$ & 7.8 & 42.1 & $<0.0001$ \\
\hline GGT $>38 \mathrm{IU} / \mathrm{I}$ & 13.8 & 21.1 & 0.385 \\
\hline $\mathrm{IMT}>0.8 \mathrm{~mm}$ & 16.7 & 40.0 & 0.01 \\
\hline Carotid plaque & 18.0 & 25.0 & 0.438 \\
\hline $\mathrm{IMT}>0.8 \mathrm{~mm}$ or carotid plaque & 23.0 & 55.0 & 0.004 \\
\hline
\end{tabular}

Table 2 Frequency of pathological clinical and ultrasonographic parameters and the significance of their differences in individuals with and without hepatic steatosis diagnosed by ultrasonography. 


\begin{tabular}{|c|c|c|c|c|c|}
\hline Logistic regression & Parameter & p-value & Odds ratio & lower (95\%) & upper (95\%) \\
\hline \multirow[t]{4}{*}{$\mathrm{IMT}>0.8 \mathrm{~mm}$} & Age [years] & $<0.0001$ & 1.080 & 1.062 & 1.099 \\
\hline & Male sex & 0.001 & 1.995 & 1.326 & 3.001 \\
\hline & BMI $\left[\mathrm{kg} / \mathrm{m}^{2}\right]$ & 0.197 & 1.034 & 0.983 & 1.088 \\
\hline & Steatosis & 0.031 & 1.583 & 1.042 & 2.403 \\
\hline \multirow[t]{4}{*}{ Carotid plaque } & Age [years] & $<0.0001$ & 1.108 & 1.087 & 1.131 \\
\hline & Male sex & 0.018 & 1.669 & 1.091 & 2.554 \\
\hline & BMI $\left[\mathrm{kg} / \mathrm{m}^{2}\right]$ & 0.907 & 1.003 & 0.950 & 1.059 \\
\hline & Steatosis & 0.019 & 1.714 & 1.094 & 2.684 \\
\hline $\mathrm{IMT}>0.8 \mathrm{~mm}$ & Age [years] & $<0.0001$ & 1.087 & 1.069 & 1.105 \\
\hline \multirow[t]{3}{*}{ or plaque } & Male sex & 0.009 & 1.659 & 0.134 & 2.427 \\
\hline & BMI $\left[\mathrm{kg} / \mathrm{m}^{2}\right]$ & 0.502 & 1.017 & 0.968 & 1.069 \\
\hline & Steatosis & 0.009 & 1.730 & 1.149 & 2.605 \\
\hline IMT >0.8 mm & Age [years] & $<0.0001$ & 1.089 & 1.068 & 1.111 \\
\hline \multirow[t]{10}{*}{ or plaque } & Male sex & 0.369 & 1.252 & 0.766 & 2.046 \\
\hline & BMI $\left[\mathrm{kg} / \mathrm{m}^{2}\right]$ & 0.177 & 0.951 & 0.883 & 1.023 \\
\hline & $\mathrm{BZ}[\mathrm{mg} / \mathrm{dl}]$ & 0.150 & 1.011 & 0.996 & 1.025 \\
\hline & HbA1c [\%] & 0.759 & 0.929 & 0.582 & 1.484 \\
\hline & $\mathrm{TG}[\mathrm{mg} / \mathrm{dl}]$ & 0.113 & 1.003 & 0.999 & 1.006 \\
\hline & $\mathrm{HDL}-\mathrm{C}[\mathrm{mg} / \mathrm{dl}]$ & 0.192 & 0.992 & 0.981 & 1.004 \\
\hline & LDL-C [mg/dl] & 0.061 & 1.005 & 1.000 & 1.011 \\
\hline & Lipoprotein(a) [mg/dl] & 0.009 & 1.007 & 1.002 & 1.012 \\
\hline & Hypertension & 0.573 & 1.144 & 0.717 & 1.826 \\
\hline & Steatosis & 0.021 & 1.773 & 1.092 & 2.880 \\
\hline
\end{tabular}

Table 3 Logistic regression of clinical parameters as to prediction of an intima media thickness $>0.8 \mathrm{~mm}$ in the common carotid arteries or plaques in the common carotid arteries or bulbi.

\section{Discussion}

$\nabla$

The results of this study clearly indicate that hepatic steatosis as diagnosed by abdominal ultrasonography is a valid marker of developing atherosclerosis in otherwise healthy people in a preventive check-up setup: to our knowledge, this is the first study demonstrating this correlation in an outpatient population of otherwise healthy individuals. The multivariate analysis even implies that hepatic steatosis adds to the effects of the major cardiovascular risk factors. It has been suggested that cardiovascular disease is the most important factor of outcome in patients with non alcoholic fatty liver disease and determinates the life expectancy much more than the progression of liver disease itself. Not only intima media thickness is increased, but there is also an impairment of flow-mediated vasodilation [16].

It has been shown that the presence of non-alcoholic fatty liver disease diagnosed by ultrasound is independently associated with an increased prevalence of ischemic heart disease $[17,18]$. The SHIP study, a large population based study in Northern Germany, showed in a 5- and 10-year follow-up that patients with a fatty liver had a significant higher morbidity and mortality than patients without this condition $[19,20]$.

Certainly, the cohort under investigation is not a representative population. However, this has been judged not to be necessary to answer the very practical question, whether it is sensible to recommend cardiovascular diagnostics based on the finding of hepatic steatosis in a thus far healthy population. Also, the accuracy of ultrasound for the detection of steatosis is not crucial in this respect, although it has been found reasonably specific $[9,21,22]$. The strength of this study is the retrospective design, since no study objective could have possibly prejudiced the results of the ultrasonographic investigation and examination bias is omitted. Furthermore, the scheduling in the center does not allow sharing knowledge with the investigator regarding results of laboratory values, cardiac echo or ECG at the time of the abdominal ultrasound.
In our study, hepatic steatosis diagnosed by abdominal ultrasound turned out to be stronger than any individual major cardiovascular risk factor, but for lipoprotein(a) to predict subclinical atherosclerosis of the carotid arteries. This is probably due to the fact that ectopic fat is a major causal factor for the components of the metabolic syndrome; thus, hepatic steatosis subsumes the effects of these factors similar to the definition of the metabolic syndrome [1,2].

Moreover, ultrasound demonstrates the risk pattern to the patient in real time, not only by visualizing the fatty liver, but also displaying the developing atherosclerosis of abdominal vessels.

Ultrasound is also very well-suited for follow-up exams to monitor the therapeutic success. Weight loss and physical exercise may induce normalization of liver tissue [23]. This is visually more impressive than the reduction of intima media thickness by $0.1 \mathrm{~mm}$. So, based on this study and previous experience [24], we think abdominal ultrasound to be appropriate in medical prevention, not only to evaluate the abdominal organs, but also to assess patients who are at a higher risk for cardiovascular diseases.

In summary, detecting hepatic steatosis has a diagnostic impact on the choice of therapeutic measures for the prevention of cardiovascular disease by itself, though it seems appropriate to take hepatic steatosis as a call for further classification of the induced risk factors and the impact on the arterial wall. In conclusion, this study demonstrates that the incidental finding of hepatic steatosis is an appropriate indication for further cardiovascular work-ups in times of individualized medicine and prevention, especially in men. 


\section{References}

1 Santini F, Giannetti M, Mazzeo S et al. Ultrasonographic evaluation of liver volume and the metabolic syndrome in obese women. J Endocrinol Invest 2007; 30: 104-110

2 Schlottmann K, Baer A, Lock G et al. Der sonographische Befund einer echogenen Leber ist ein Indikator einer pathologischen Glukosetoleranz. Dtsch Med Wschr 2000; 125: 517-522

3 Lizardi-Cervera J, Aguilar-Zapata D. Nonalcoholic fatty liver disease and its association with cardiovascular disease. Ann Hepatol 2009; 8 (Suppl 1): S40-S43

4 Ramilli S, Pretolani S, Muscari A et al. Carotid lesions in outpatients with non-alcoholic fatty liver disease. World J Gastroenterol 2009; 15: $4770-4774$

5 Targher G, Arcaro G. Non-alcoholic fatty liver disease and increased risk of cardiovascular disease Atherosclerosis 2007; 191: 235-240

6 Targher G, Bertolini L, Padovani R et al. Non-alcoholic fatty liver disease is associated with carotid artery wall thickness in diet controlled type 2 diabetic patients. J Endocrinol Invest 2006; 29: 55-60

7 Choi SY, Kim D, Kang JH et al. Nonalcoholic fatty liver disease as a risk factor of cardiovascular disease: relation of nonalcoholic fatty liver disease to carotid arteriosclerosis. Korean J Hepatol 2008; 14: 77-88

8 Targher $G$. Non-alcoholic fatty liver disease, the metabolic syndrome and the risk of cardiovascular disease: the plot thickens. Diabet Med 2007; 24: 1-6

9 Joseph AE, Saverymuttu SH, Al-Sam S et al. Comparison of liver histology with ultrasonography in assessing diffuse parenchymal liver disease. Clin Radiol 1991; 43: 26-31

10 Bots ML, Hoes AW, Koudstaal PJ et al. Common carotid artery intimamedia thickness and risk of stroke and myocardial infarction: the Rotterdam study. Circulation 1997; 96: 1432-1437

11 Pignoli P, Tremoli E, Poli A et al. Intimal plus medial thickness of the arterial wall: a direct measurement with ultrasound imaging. Circulation 1986; 74: 1399-1406

12 Doyon A, Kracht D, Bayazit AK et al., 4C Study Consortium. Carotid artery intima-media thickness and distensibility in children and adolescents: reference values and role of body dimensions. Hypertension 2013; Sep 62: 550-556

13 Hennerici M, Dafferthofer $M$, Meairs $S$. Ultraschalldiagnostik extra-und intrakranieller Gefäße. In: Der Schlaganfall, 2001. Hartmann A, Heiss WD (Hrsg.). Steinkopf Verlag; Darmstadt: p155 Tab. 8.2
14 Touboul PJ, Hennerici MG, Meairs $S$ et al. Mannheim carotid intimamedia thickness and plaque consensus (2004-2006-2011). An update on behalf of the advisory board of the 3rd, 4th and 5th watching the risk symposia, at the 13th, 15th and 20th European Stroke Conferences, Mannheim, Germany, 2004, Brussels, Belgium, 2006, and Hamburg, Germany, 2011. Cerebrovasc Dis 2012; 34: 290-296

15 Alberti KG, Eckel RH, Grundy SM et al. Harmonizing the metabolic syndrome: a joint interim statement of the International Diabetes Federation Task Force on Epidemiology and Prevention; National Heart, Lung, and Blood Institute; American Heart Association; World Heart Federation; International Atherosclerosis Society; and International Association for the Study of Obesity. Circulation 2009: 120: 1640-1645

16 Targher G, Day CP, Bonora E. Risk of cardiovascular disease in patients with non-alcoholic fatty liver disease. N Engl J Med 2010; 363: $1341-1350$

17 Lin YC, Lo HM, Chen JD. Sonographic fatty liver, overweight and ischemic heart disease. World J Gastroenterol 2005; 11: 4838-4842

18 Puig J, Blasco G, Daunis-I-Estadella J et al. Nonalcoholic Fatty Liver Disease and Age Are Strong Indicators for Atherosclerosis in Morbid Obesity. Clin Endocrinol (Oxf) 2014, Dec 16 doi:10.1111/cen.12698 [Epub ahead of print]

19 Baumeister SE, Völzke H, Marschall P et al. Impact of Fatty Liver Disease on Health Care Utilization and Costs in a General Population: A 5- Year Observation. Gastroenterology 2008; 134: 85-94

20 Haring $R$, Wallaschofski $H$, Nauck $M$ et al. Hepatic Steatosis Increases Prediction of Mortality Risk From Elevated Serum Gamma-Glutamyl Transpeptidase Levels. Hepatology 2009; 50: 1403-1411

21 Mishra P, Younossi ZM. Abdominal ultrasound for diagnosis of nonalcoholic fatty liver disease (NAFLD). Am J Gastroenterol 2007; 102: 2716-2717

22 Williams $C D$, Stengel J, Asike MI et al. Prevalence of nonalcoholic fatty liver disease and nonalcoholic steatohepatitis among a largely middleaged population utilizing ultrasound and liver biopsy: a prospective study. Gastroenterology 2011; 140: 124-131

23 Shulman GI. Ectopic fat in insulin resistance, dyslipidemia and cardiometabolic disease. N Engl J Med 2014; 371: 1331-1341

24 Guth S, Leise U, Gocke $C$ et al. Ultrasound versus MRI in Preventive Examinations - A Retrospective Analysis. Ultraschall in Med 2012; 33: E202-E209 